\title{
Modeling and Identification of Hidden Objects in Dynamic Systems using Digital Filters.
}

\author{
${ }^{1 s t}$ Fkirin, M. A . Dept. of Industrial and \\ Control Eng., faculty of Electronic \\ Eng., Minufiya University. Menof, \\ Egypt. Corresponding authors: \\ mafkirin@el-eng.menofia.edu.eg.
}

\author{
${ }^{3 r d}$ El-Deery, M. F.Section Head @ \\ Agiba Petroleum Company. Engineer, \\ Naser city, Cairo, Egypt. Email: \\ engmohamed.eldeery@gmail.com
}

\begin{abstract}
Digital filters are used for identification, prediction, and modeling of hidden objects in dynamic systems. These filters are Gaussian filter with power spectrum depth estimation, edge detection of the hidden objects as well as constructed 2-D geomagnetic modeling of hidden objects. In this paper, digital filter results are obtained by MATLAB software. Magnetometer instrument is used to collect aeromagnetic data of dynamic systems. Aeromagnetic data are collected from Aswan area in Egypt. MATLAB codes are built to insert data and process this data in user graphic interface (UGI). The estimated depth level of hidden objects in dynamic system is selected via the power spectrum which used to transform processed data in time domain to frequency domain. Then, figure out the hidden objects in shallow and deeper levels. Edge boundary is implemented to obtain hidden objects dynamic system either shallow and deep levels. Edges and clearness hidden objects dynamic systems take out by smoothing total horizontal derivative (THDR) and enhanced total horizontal derivative (ETHDR) filter. The estimation depth of hidden objects and their extension are calculated from the 2-D modeling filter. Also, the 2-D model shown the difference hidden objects dynamic systems types through there magnetic susceptibility.
\end{abstract}

Keywords-Identification, Modeling, Hidden Objects, Aeromagnetic Data, Digital Filters.

\section{INTRODUCTION}

Digital filters are used for solving real problems [1]. Data is collected by an aeromagnetic survey. The hidden objects are located as shown in figure (1), they exist as eleven objects [2]. These objects are followed up by digital filters. The mathematical algorithms of digital filters are simplified by MATLAB codes. MATLAB codes are built to know and extract the hidden objects (Potensoft) [3]. MATLAB codes that applied as shown in the chart (1). The digital filters applied as, Power spectrum (PS), edges detection and 2-D modeling. The power spectrum is applied at a different level by Gaussian low and high pass filters [4]. The edge detection filters are approximated dataset to figure out subsurface facts. The edge detection filters are applied to clear shallow and deep hidden objects. The edge detection is important to extract edges and extend boundaries. These filters are used to boundary edges and sharp edges of the hidden objects. Hidden objects are estimated via a 2-D modeling algorithm. depths and relief of the hidden objects (basement surface) across two profiles are defined, as well as depths and shapes of hidden objects. 2-D modeling defined hidden object types by their magnetic susceptibility [5].

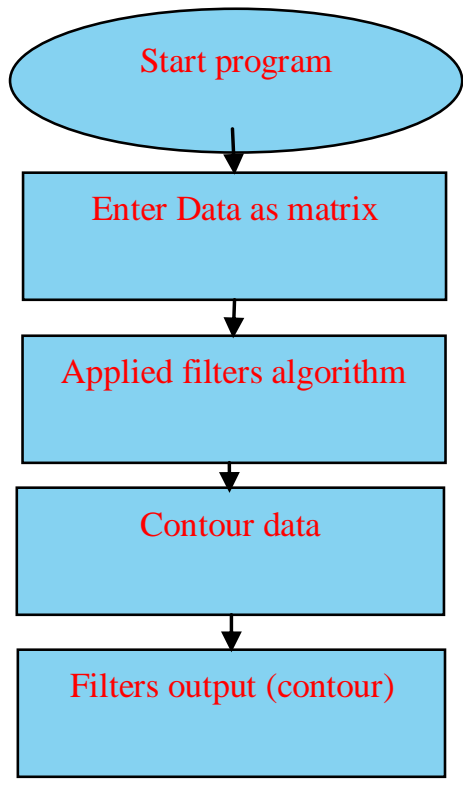

Flow Chart (1): MATLAB codes.

\section{MAGNETIC DATA DESCRIPTION}

The aeromagnetic data field of the study area are available through The MPGAP project (cooperation among the Egyptian General Petroleum Corporation (EGPC), the Egyptian Geological Survey and Mining Authority (EGSMA) and Aero-Service Division, Western Geophysical Company of America) Aero-service [6]. plans the parallel traverse lines measured in $\mathrm{N} 45 \mathrm{oE}$ direction, with a spacing of $1 \mathrm{~km}$ approximately. The tie lines were perpendicular to the parallel traverse lines (took $\mathrm{N} 135 \mathrm{oE}$ direction) and spaced with about $10 \mathrm{~km}$. The average terrain clearance is of $120 \mathrm{~m}$. The data are three columns the first and second columns are $\mathrm{x}$ and $\mathrm{y}$ directions, the third column represented magnetic data collection. MATLAB code is drawn $\mathrm{x}$ and $\mathrm{y}-$ direction and contoured magnetic data as shown in Figure (1). All categories of data are contoured with the same colors. The closed or semi-closed contours are represented as hidden objects that labeled with the black number as shown in Figure (1). The process data are performed in a Fast Fourier Transform (FFT) technique which is required to covert the measured data from the time domain to the frequency domain (wavenumber domain). The frequency wavenumber is defined by several wavelengths per unit distance. To obtain wave number $(\mathrm{k}), \mathrm{v}=1 / \lambda=\mathrm{f} / \mathrm{v}$ where: wave number $\mathrm{k}=2 \pi / \lambda=2 \pi \mathrm{f} / \mathrm{v}$. 


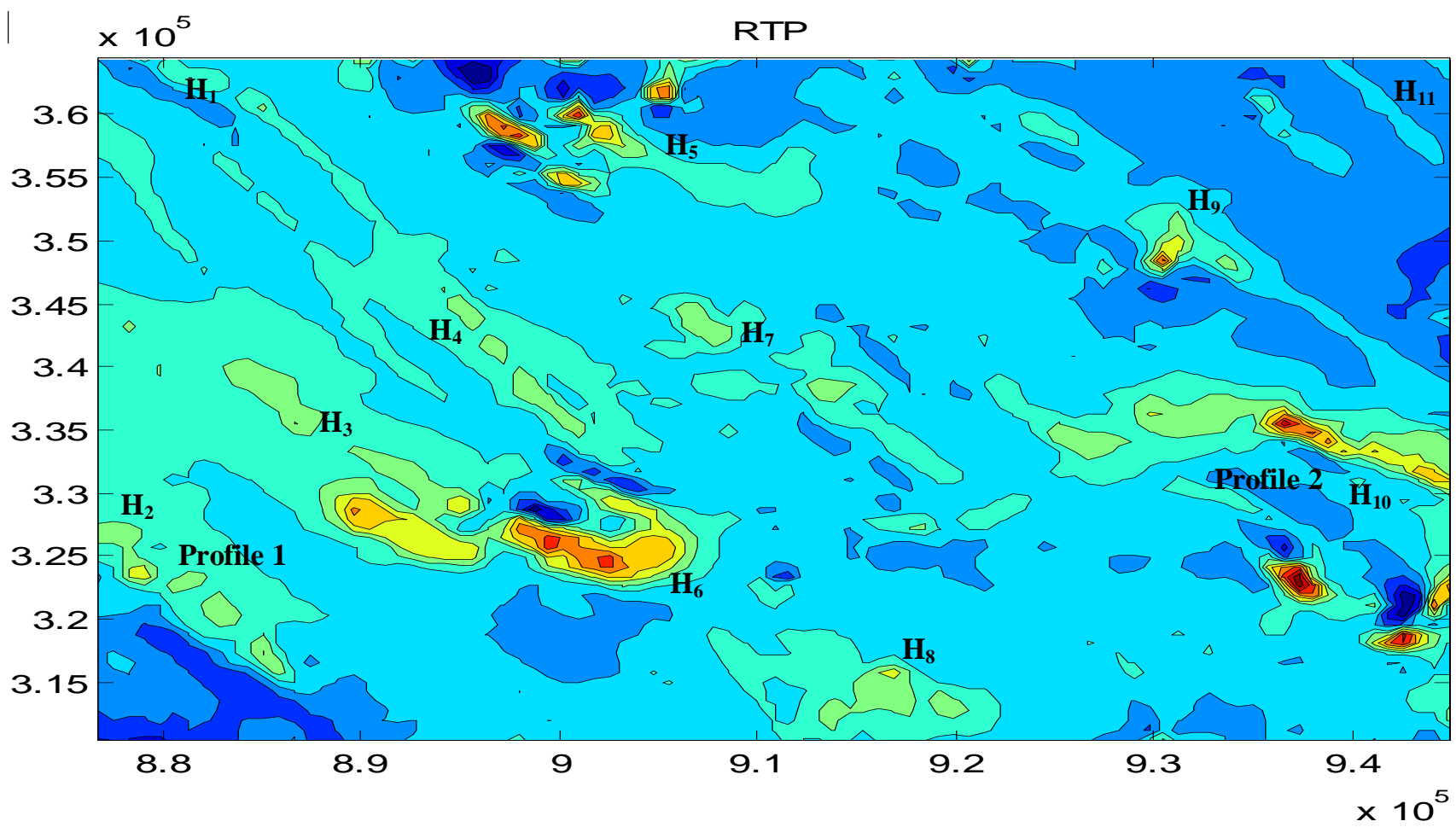

Fig. 1 RTP locations of the hidden objects.

Frist entry data in MATLAB as an excel file, then convert the data as a matrix form. RTP contour algorithm is represented in Equation (1) [7].

$L(\theta)=\frac{1}{[\sin (I)+i \cos (D-\theta) \cos (I)]^{2}}$

Where, $\Theta$ is wavenumber direction, $I$ is magnetic inclination and $\mathrm{D}$ is magnetic declination.

RTP contour result, all the eleven anomalies (H1, H2, .., H11) in the resultant reduced to pole (RTP) magnetic figure located directly above the sources as well as having high magnetic susceptibility.

\section{POWER SPECTRUM AND GAUSSIAN FILTER}

In the present study, the analysis of the power spectrum curve and the Gaussian filters techniques are applied on the RTP magnetic data to produce the residual hidden objects (near-surface) at $600 \mathrm{~m}$ and the Regional hidden objects (deep-seated) at $1.5 \mathrm{~km}$ as shown in Figure (2a). The analysis of the power spectrum curve, the separation deep-seated hidden objects frequency varies from 0.0 to 0.18 cycles $/ \mathrm{Km}$, while the separation near-surface hidden objects frequency ranges from 0.18 to 0.3 cycles/ $\mathrm{Km}$. These bands of frequencies produced by the Gaussian low-pass deep objects as shown in figure $2 \mathrm{~b}$ and Gaussian high-pass produced deeper objects as shown in Figure (2c) respectively. Hidden objects depth estimated by equation (2) algorithm [8], [9].
$P(k)=C k^{\beta} \exp (-2 \mathrm{hk})$

Where $\beta$ is spectral exponent, $h$ is measured distance of observed plane to top of hidden objects, $\mathrm{c}$ is constant of magnetic intensity of hidden objects and $\mathrm{k}$ is wave number $=$ $1 / \lambda, e^{ \pm 2 \pi h \sqrt{u^{2}+v^{2}}}, \mathrm{~h}$ is depth of hidden objects and $\mathrm{u} / \mathrm{v}$ frequency domain variable.

Average depth calculated for the deep and shallow hidden objects from the power spectrum curve for the whole area attained $1.5 \mathrm{~km}$ and $0.6 \mathrm{~km}$, respectively. The measured magnetic data are containing fractal data and depth as inherent in the present power spectrum model. The separation plane of the hidden objects is calculated from the power spectrum curve as minus selected slope segment divide by $4 \pi$. The low-pass and high-pass filters used to determine the deep and shallow structural features affecting on study area [10]. These features help to provide a satisfactory picture of the basement configuration and determine the structural pattern of the study area. The results of the Gaussian low pass filter shown three large groups with a large extension of deep objects as shown in figure (2b) with attenuated H11 object, as shown in figure (2a) the deeper objects 1, $2 \& 3$ are hidden objects H1....H10. On the other hand, increase these extensions with the Gaussian high pass filter as shown in figure (2c) with a surface seated component. 

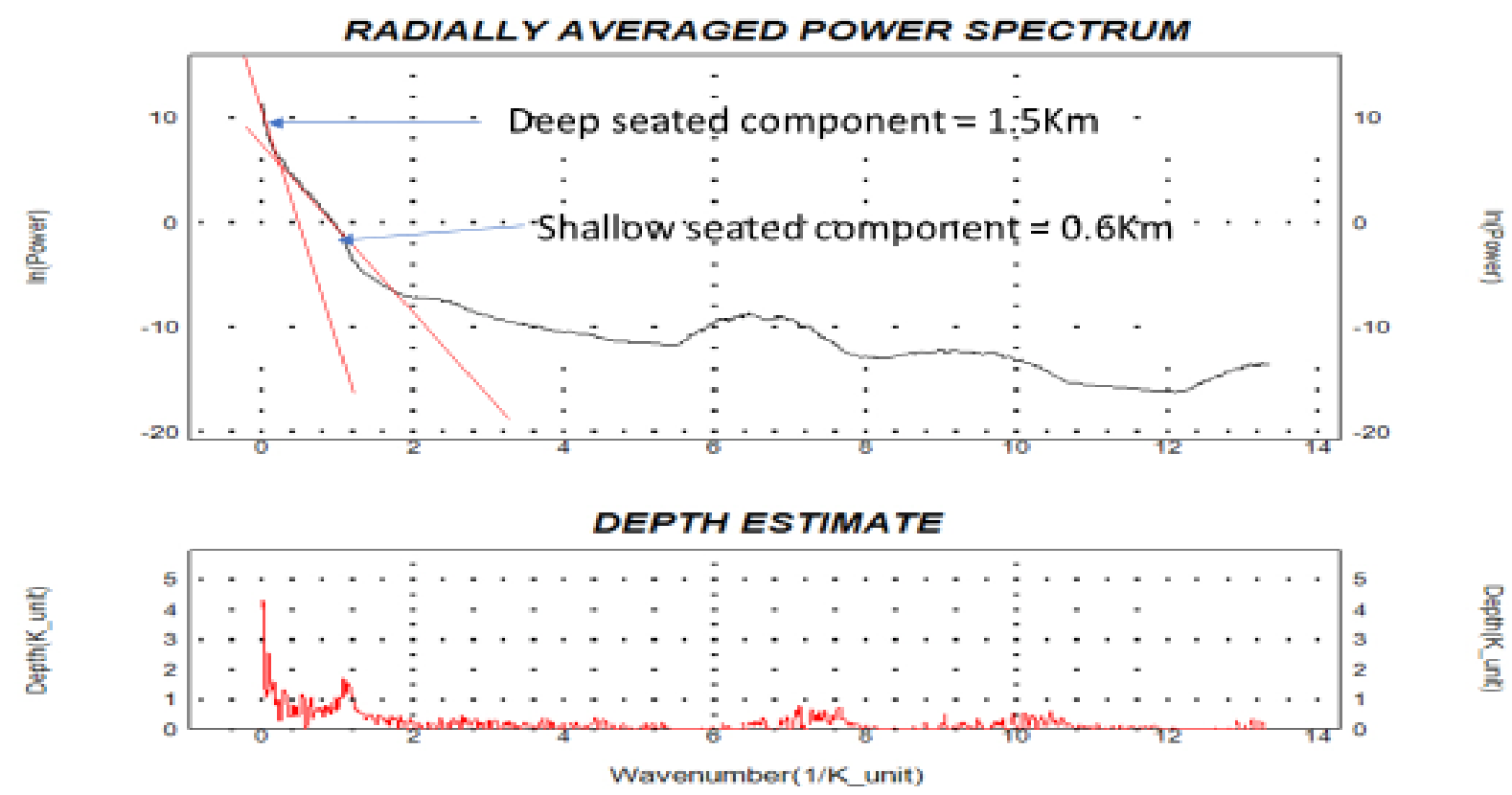

Fig. 2a Power spectrum curve and depth estimation for deep and shallow components of the study area.

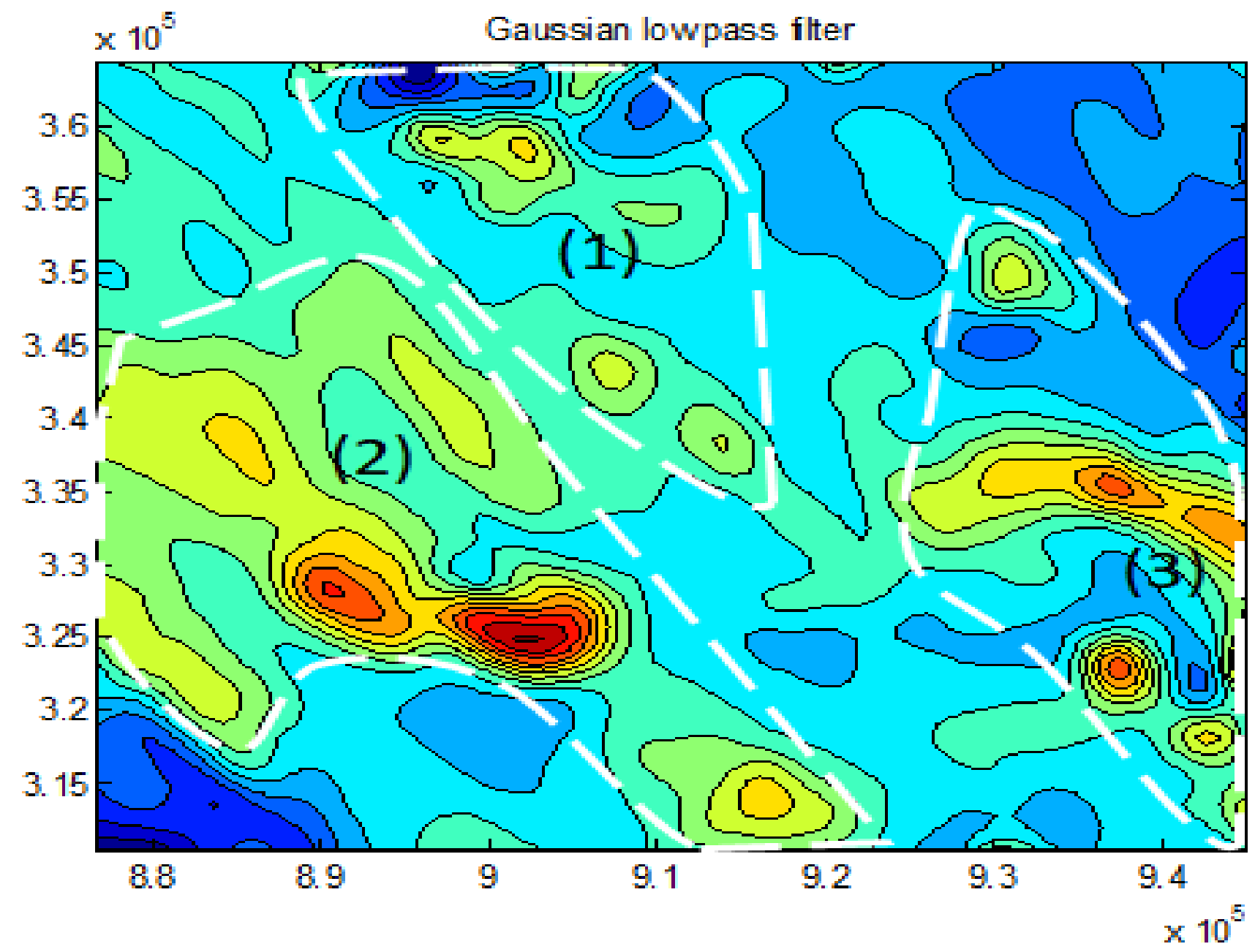

Fig. 2b Gaussian low pass filter deep objects. 


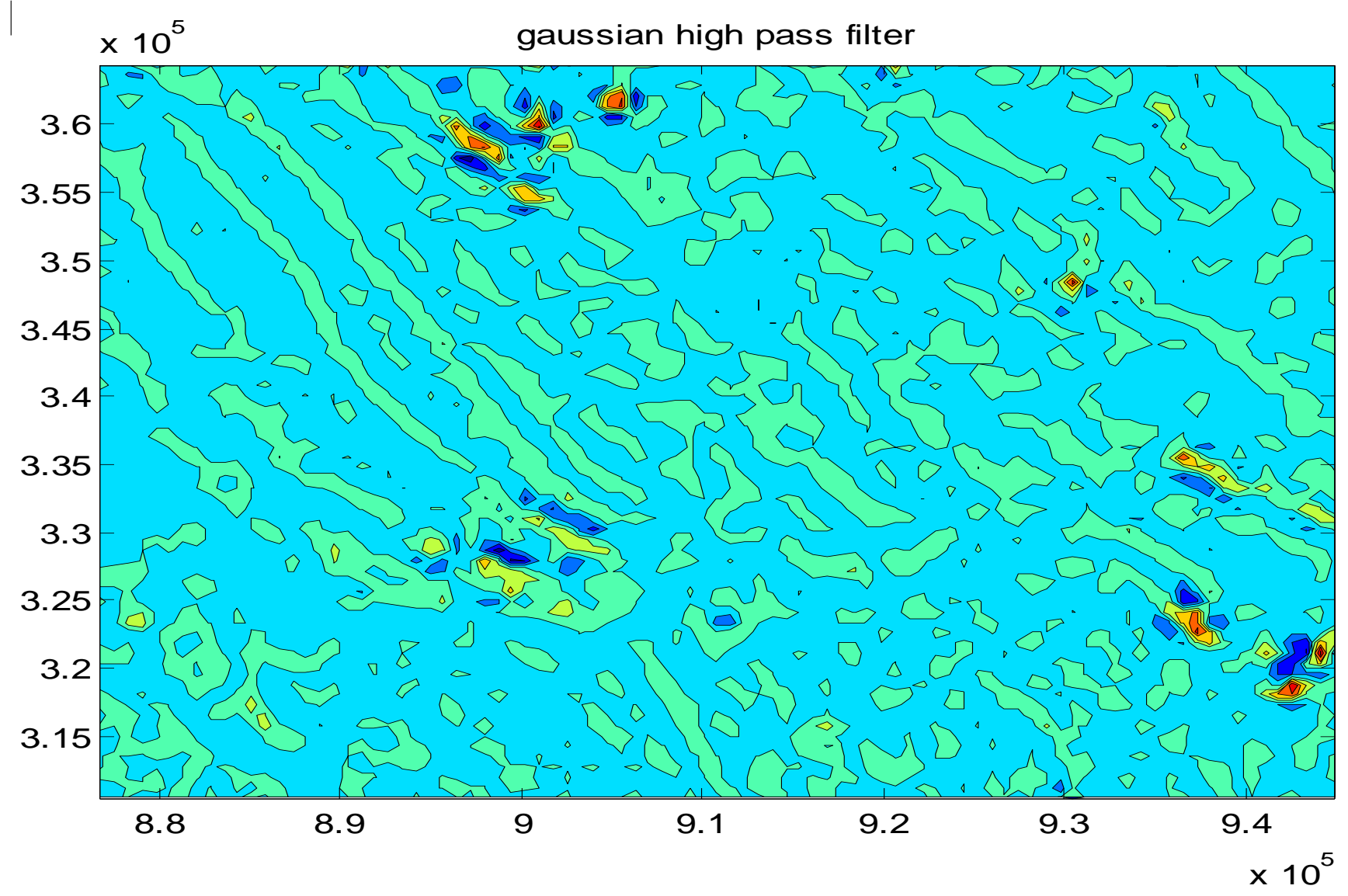

Fig. 2c Gaussian high pass filter shallow objects.

\section{Edge Detection Digital Filter}

In literature [11], many smoothing digital techniques have been adopted for edge detection. Edge detection filter as a total horizontal derivative. The said filters used to remove the noises from data, as well as delineate hidden objects in shallow and deeper subsurface [12]. The edge detection filters are accurate filters for showing the hidden objects extensions. Edge detection filters as, total horizontal derivative (THDR) is introduced in equation (4) [13], [14].

$\mathrm{THDR}=\sqrt{\left(\frac{\partial M}{\partial x}\right)^{2}+\left(\frac{\delta M}{\delta y}\right)^{2}}$

where: $\partial \mathrm{M} / \partial \mathrm{x}$ and $\partial \mathrm{M} / \partial \mathrm{y}$ are the first horizontal derivative of magnetic data in $\mathrm{x}$ direction and the second horizontal derivative of magnetic data in y direction, respectively.

THDR is more effected in shallow objects than deeper bodies as illustrated in figure (3a), in the two orthogonal horizontal derivatives of the magnetic field. Most trends of the positive magnetic sources are cleared in the NW-SE direction. The shallow objects are shown as tunnel. The enhanced total horizontal derivative (ETHDR) is applied in this paper. It is applied on the potential field data. ETHDR (it is called Etilt) explain how to deduce hidden objects [15], the ETilt filter is arctan to the ratio of the vertical derivative to the total horizontal derivative of the analytical signal and secondly. ETHDR delineates the best accurate edges of all bodies better than the filter above, as it produced very sharp gradients over the edges of the bodies (objects) in either shallow and deeper together as shown in figure (3b). Etilt is clear the structural interpretation and accurate location [16], [17]. Hidden objects as shown in figure (3b) H1 to H11 and near to surface objects. 


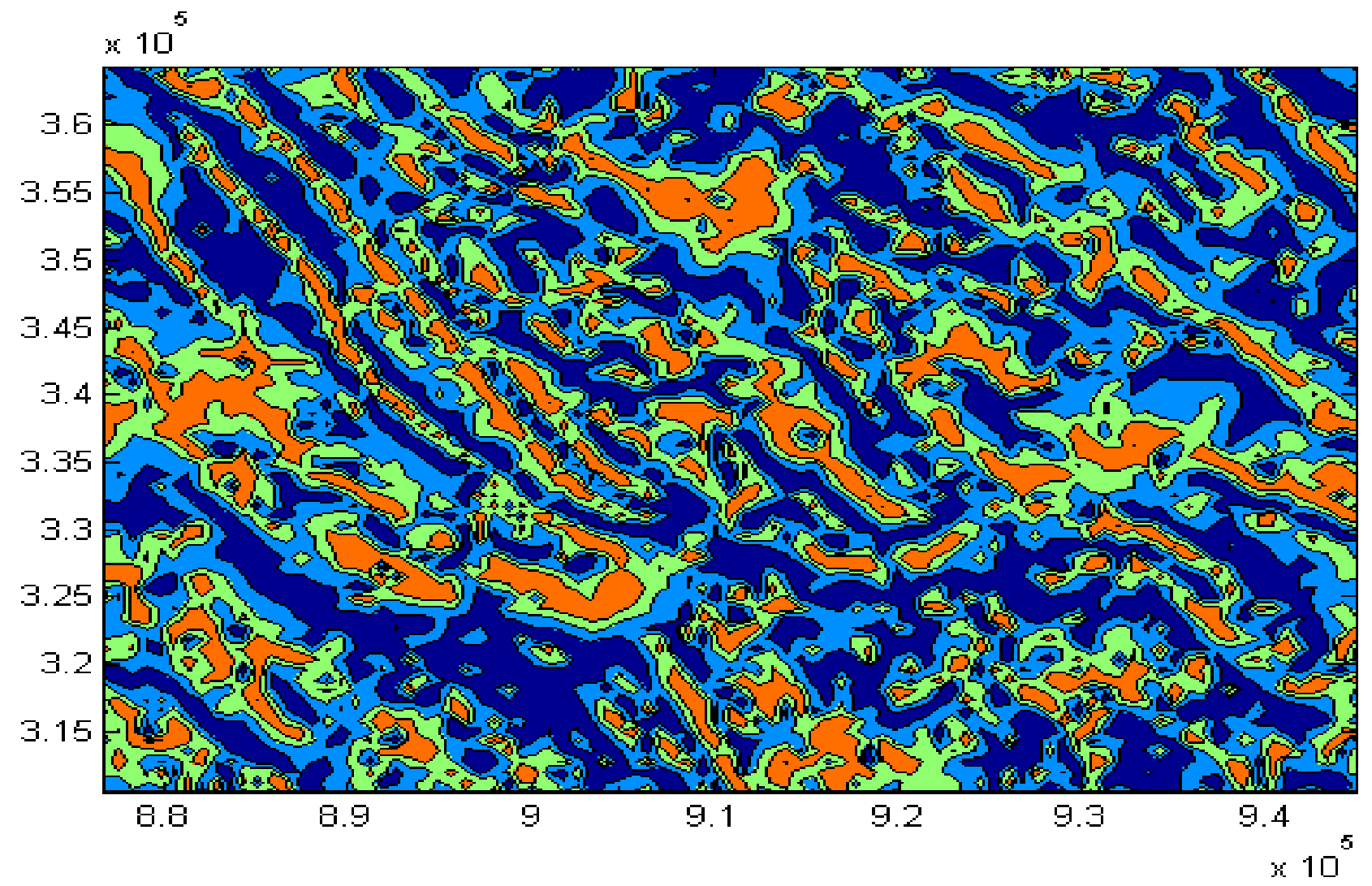

Fig. 3a Magnetic Total horizontal derivative map of the study area.

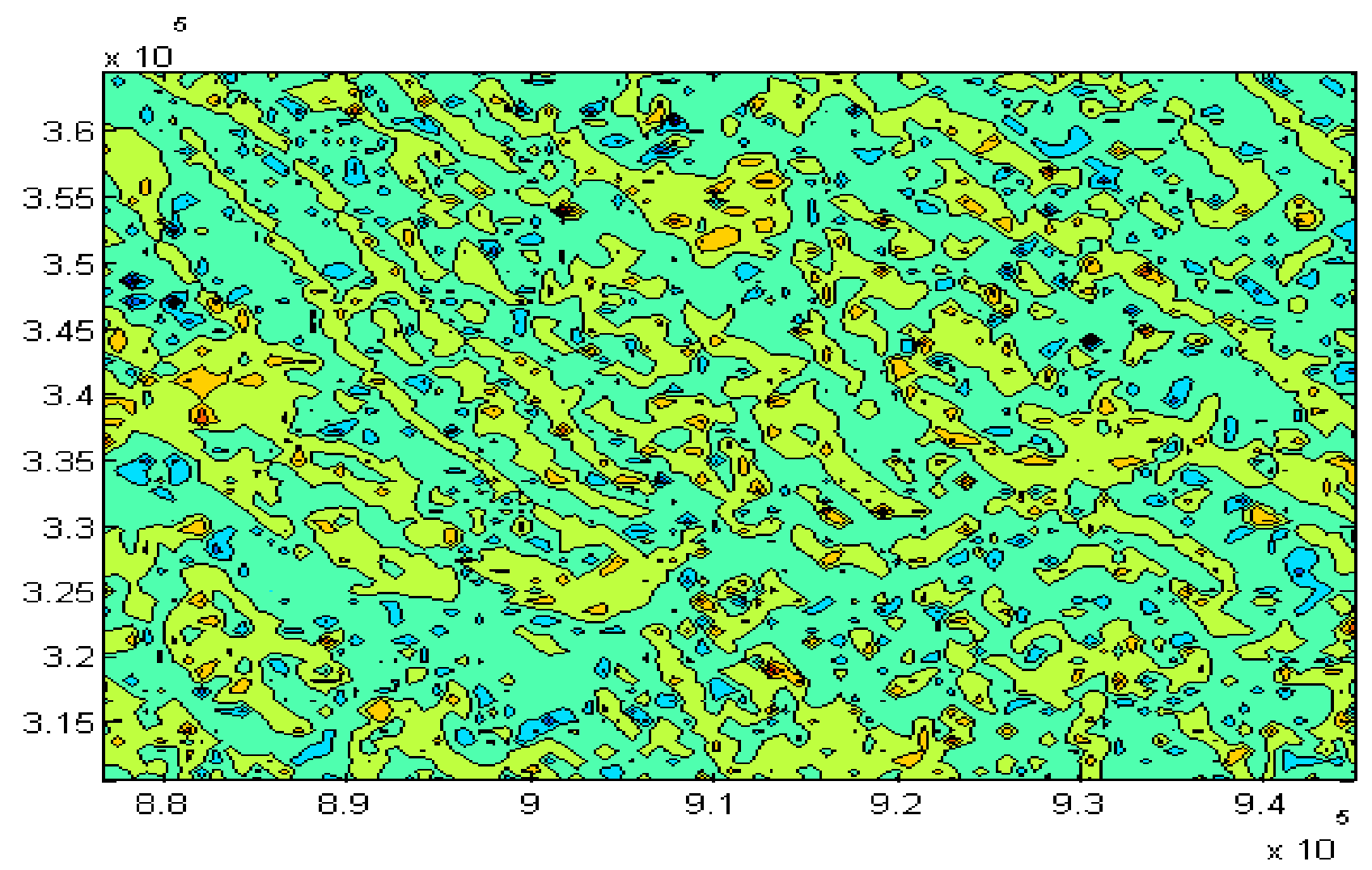

Fig. 3b Magnetic ETHDR map of the study area. 


\section{2-D MODELING Digital FiLTER.}

2-D modeling is used to show the shapes of the hidden object's occurrences. The modeling method is strong for the detection of hidden objects that appears by magnetic susceptibility contrast. 2-D modeling is useful to clear potent diversity in magnetic susceptibility, shape, upper surface and the appearance of sundry profound features of hidden objects. So, the modeling method algorithm shown equation (5) [18] - [20]. The RTP figure is shown the location of two geomagnetic profiles that are selected for modeling two hidden objects expanded on the subsurface. The changes of magnetic susceptibility in this manuscript reflect the basement relief in the subsurface.

$S=\sum\left[W_{i}\left[T_{i}-\left(T_{0}+a\left(x_{i}-x_{0}\right)+a\left(x_{i}-x_{0}\right)^{2}\right)-\right.\right.$ where: xi: is the range from the starting of the section of scanning line being suit, $\mathrm{Ti}$ is the spotted magnetic objects rate, $\mathrm{T} 0$ is the sectional surrounding level at $\mathrm{x}=0$, $\mathrm{a}$ is the slope of the sectional surrounding, $b$ is 2 nd derivative of the sectional surrounding, $\mathrm{f}$ is the theoretic magnetic objects rate, $\mathrm{x}$ is direction of position point of the top-level surface of objects, $\mathrm{Wi}$ is the weight assigned to the observation xi The adjustable model parameters are magnetizations (M), ratio of remain to magnetizations $(\mathrm{Q})$, remain inclination (i), remain declination (c), dip (d), depth (h), thickness (t), half-width $(\mathrm{x})$, and half-length (y). through magnetic inclination (I), magnetic declination (D), beat perpendicular (S), and line direction $(\mathrm{P})$ are stable parameters.

The hidden object extracted types depends on their magnetic susceptibility contrast [21]. Two profile shown depth and types of hidden objects as shown in figures ( $4 \mathrm{a} \& 4 \mathrm{~b})$. hidden objects as shown in figure (4-a) are expended depth from 535 to $3102 \mathrm{~m}$, average object width is $392 \mathrm{~m}$ and magnetic susceptibility recorded 0.002 to 0.009 (emu). hidden objects as shown in figure (4b) are expended from 300 to $3425 \mathrm{~m}$, average object width is $1900 \mathrm{~m}$ and magnetic susceptibility recorded 0.002 to 0.009 (emu) [22]. In these modeling shown the hidden objects types based on magnetic.

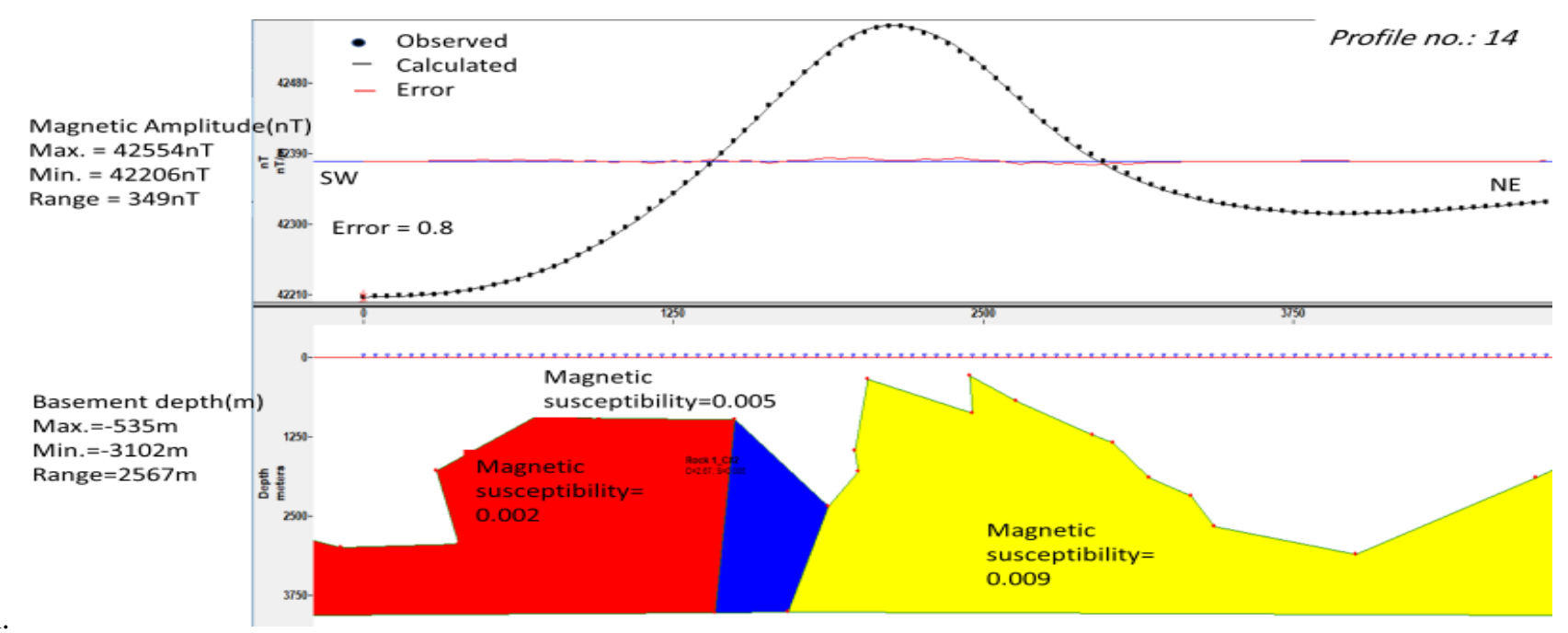

$B$.

Fig. 4a 2-D modeling of hidden object No. 2.

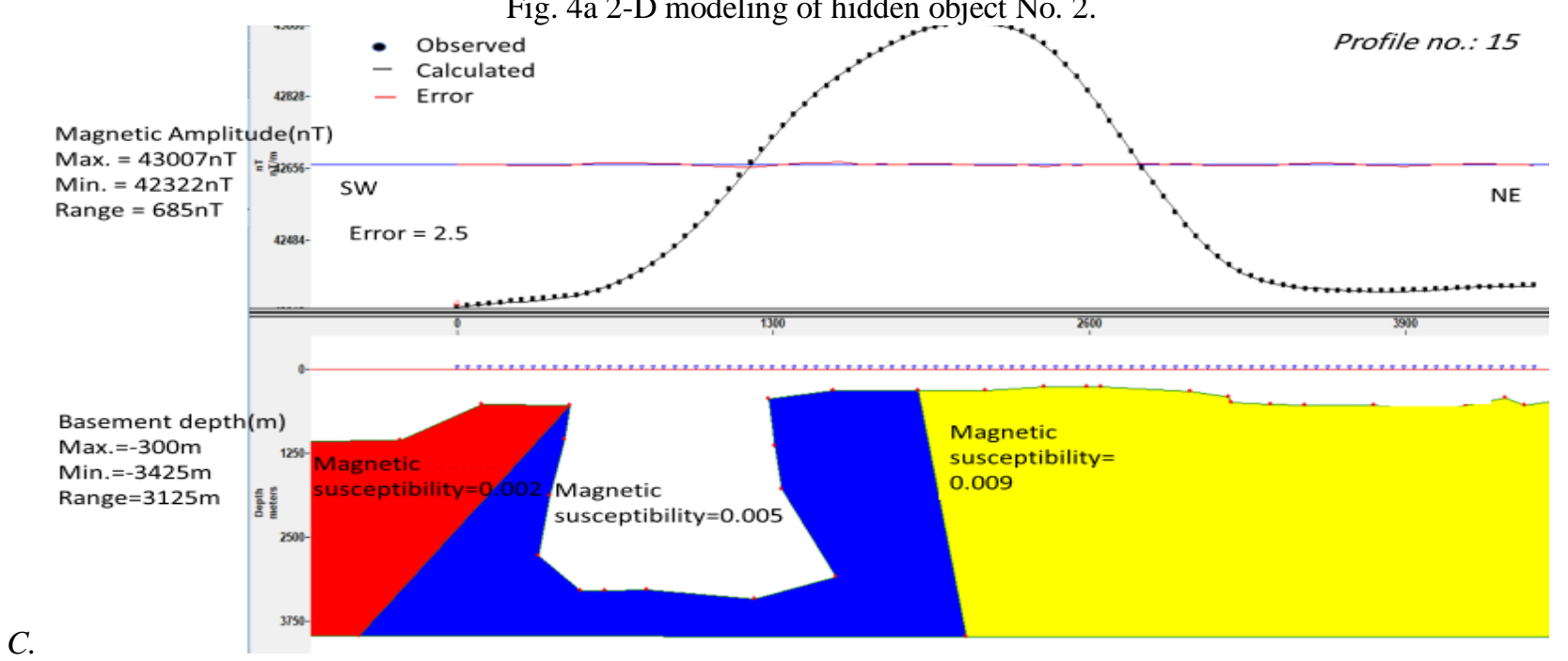

D.

Fig. 4b 2-D modeling of hidden object No. 9. 


\section{ACKNOWLEDGMENTS}

AEROMAGNETIC DATA WERE PROVIDED BY THE MPGAP PROJECT (COOPERATION AMONG THE EGYPTIAN GENERAL Petroleum Corporation (EGPC)), Egypt. Many THANKS FOR THEIR SUPPORT.

\section{CONCLUSIONS}

Identification and modeling of hidden objects in dynamic systems are enhanced by using digital filters. RTP figure shown some high amplitude signatures nearly NE-SW trends. The Power Spectrum used to estimate the regional and residual components by drawing tangent for Gaussian filters, the depth of the shallow objects is calculated at 600 $\mathrm{m}$, while the depth of the deep object is computed at 1500 m. The Gaussian filters recognize hidden objects both separated components as shown in Gaussian low and high pass filter results. The main concluded result is clearly disappearing hidden objects in the Gaussian low pass filter (deep objects) and appear clearly in the Gaussian high pass filter (shallow objects) of the study area. Total horizontal derivative and enhanced total horizontal derivative is used to boundaries hidden objects in shallow and deep. The enhancement total horizontal derivative is more effective in sharply objects boundaries. It also used to detect the extension of objects. 2-D modeling used to follow up hidden objects geomagnetic structure. By focusing on the hidden objects, depth, magnetic susceptibility contrast, and extension (shape) are fitted by using 2-D modeling. The hidden object depths are ranged $300 \mathrm{~m}$ to $3500 \mathrm{~m}$ and the type of the hidden object is ferromagnetic material based on estimated magnetic susceptibility 0.005 .

\section{REFERENCES}

[1] R. Mendes, L. Hardouin and M. Lhommeau, "Stochastic Filtering of Max-Plus Linear Systems with Bounded Disturbances," in IEEE Transactions on Automatic Control, Vol. 64, Issue 9, pp. 3706-3715, Sept. 2019

[2] Y. Deng, Y. Chen, P. Wang, "Magmatic underplating beneath the Emeishan large igneous province (South China) revealed by the COMGRA-ELIP experiment". Tectonophysics Vol. 672, Issue 673, pp. 16-23, Mar. 2016.

[3] M. Özgü Arısoy and Ü nal Dikmen . Potensoft: "MATLAB-based software for potential field data processing, modeling and mapping", Computers \& Geosciences Vol. 37, Issue 7, pp 935-942, July 2011.

[4] P. Nwogbo, "Spectral prediction of magnetic source depths from simple numerical models", Computers \& Geosciences, Vol. 24, Issue 9, pp. 847-852, Nov. 1998.

[5] L. Yaoguo, G. Sarah, A. Devriese, "Enhancement of Magnetic Data by Stable Downward Continuation for UXO Application". IEEE Transactions on Geoscience and Remote SensingSociety Vol. 51, Issue 6, pp. 3605 - 3614, Jun., 2013.

[6] Aero-Service the Egyptian General Petroleum Corporation. "Final operational report of airborne magnetic/radiation survey in the Eastern Desert, Egypt for the Egyptian General Petroleum Corporation." Aero-Service, Houston, Texas, April, 1984.

[7] V. Baranov, H. Naudy, "Numerical calculation of the formula of reduction to the magnetic pole". Geophysics Vol. 29, Issue 1, pp. $67-$ 79, Fab., 1964.

[8] J. Garcia-Abdeslem, G. Ness, "Inversion of the power spectrum from magnetic anomalies", Geophysics, Vol. 59, Issue 3, pp. 391-401, Mar. 1994.

[9] A. Alagbe, "Depth Estimation from Aeromagnetic Data of Kam", International Journal of Advanced Research in Physical Science, Vol. 2, Issue 1, pp 37-52, Jan. 2015.
[10] T. Alasi, Z. Ugwu, M. Ugwu, "Estimation of sedimentary thickness using spectral analysis of aeromagnetic data over Abakaliki and Ugep areas of the Lower Benue Trough, Nigeria", International Journal of Physical Sciences, Vol. 12, Issue 21, pp. 270-279, 16 Nov. 2017.

[11] N. Daniel, N. Mirianrita, O. Emmanuel, "A case study of aeromagnetic data interpretation of Nsukka area, Enugu State, Nigeria, for hydrocarbon exploration", International Journal of Physical Sciences, Vol. 10, Issue 17, pp. 503-519, Sep. 2015.

[12] G. Miller, V. Singh, "Potential field tilt a new concept for location of potential filed sources" Journal of Applied Geophysics Vol. Issue 32, pp. 213-217, Aug. 1994.

[13] Juneja M, Sandhu P, "Performance Evaluation of Edge Detection Techniques for Images in Spatial Domain". International Journal of Computer Theory and Engineering, Vol. 1, Issue 5, pp. 1793-8201, Dec. 2009.

[14] S. Oliveiraa, F. Ferreirab, J. Souzac, "Edge Detect PFI: An algorithm for automatic edge detection in potential field anomaly images application to dike-like magnetic structures". Computers \& Geosciences, Vol. 103, pp. 80-91, Jun. 2017.

[15] L. Cordell, V. Grauch, "Mapping basement magnetization zones from aeromagnetic data in the San Juan basin, New Mexico. In Hinzc W.J. (Ed.). The utility of regional gravity and magnetic anomaly maps", Society of Exploration Geophysicists, Vol. 5, Issue 12, pp. 181-197, Nov. 1985.

[16] S. Agus, Y. Harri, N. Jun, "Horizontal Gradient Analysis for Gravity and Magnetic Data Beneath Gedongsongo Geothermal Manifestations, Ungaran, Indonesia", Proceedings World Geothermal Congress 2015 Melbourne, Australia, 19-25 April 2015.

[17] M. Arisoy, U. Dikmen, "Edge Detection of Magnetic Sources Using Enhanced Total Horizontal Derivative of the Tilt". Bulletin of the Earth Sciences Application and Research Centre of Hacettepe University, Yerbilimleri Vol., 3, Issue 4, pp. 73-82, Mar. 2013.

[18] K. Karimi, F. Shirzaditabar, "Using the ratio of the magnetic field to the analytic signal of the magnetic gradient tensor in determining the position of simple shaped magnetic anomalies". Journal of Geophysics and Engineering, Vol. 14, Issue 4, pp. 769-779, Aug. 2017.

[19] H. Asadi, M. Hale, "A predictive GIS model for mapping potential gold and base metal mineralization in Takab area, Iran". Computers \& Geosciences, Vol. 27, Issue 8, pp. 901-912, Oct. 2001.

[20] S. Ahmed, U. Keisuke, S. Abuelhoda, "Spectral Analysis of Aeromagnetic Data for Geothermal Reconnaissance of Quseir Area, Northern Red Sea, Egypt", Proceedings World Geothermal Congress 2000, Vol. 1, Jun. 2000.

[21] A. Abdou-Khalaf, K. Pavel, K. Ahmed, "Interpretation of Geophysical Data at EL Fayoum-Dahshour Area, Egypt Using Three Dimensional Models", Arabian Journal for Science and Engineering, Vol. Issue 38, pp.1769-1784, Nov. 2012.

[22] S. Stocco, A. Godio, L. Sambuelli, "Modelling and compact inversion of magnetic data: A Matlab code", Computers \& Geosciences, Vol, 35. Issue 10, pp. 2111-2118, Oct. 2009. 